\title{
Pattern of Sexually Transmitted Infections in Pregnant Women
}

\author{
Dr. S. Kalaivani
}

\begin{abstract}
Introduction: Women who are pregnant may become infected with sexually transmitted infections (STI).The outcome of pregnancy may be affected as the newborn get infections via perinatal transmission. Aim: To estimate the pattern of sexually transmitted infections in pregnant women attending STD OP. Materials \&Methods: A clinical retrospective study was conducted in pregnant women from January 2013 -June 2015 by history, clinical examination, laboratory investigations after informed consent. Results: Among 11959 female patients,pregnant women were 84(0.7\%) . 41(48.8\%) pregnant women had STIs with genital wart 10 (24\%), syphilis 9 (22\%),vulvovaginal candidasis 8 (19 \%),molluscum contagiosum 2(5\%), trichomoniasis, HIV +ve, and bacterial vaginosis were $2.5 \%$. Pattern of mixed infections like Early latent syphilis +VVC, VVC+ genital wart+ genital herpes, HIV+ve + herpes , HIV +ve +genital wart constitute $2.5 \%$ each. Conclusion: This study stresses the importance of Antenatal screening for HIV, Syphilis in $1^{\text {st }} \& 3^{\text {rd }}$ trimester \&partner screening.
\end{abstract}

Keywords: Pregnant Women, Sexually Transmitted Infections (STIS), HIV, Vulvovaginal Candidiasis (VVC), Genital Wart

\section{Introduction}

Sexually transmitted infections include diseases that are transmitted by sexual intercourse .It requires the presence of agent in one partner, other partner to be susceptible to infection, when engaged in sexual practices. ${ }^{1}$ STI are prevalent in teenagers \& young adults .

In pregnancy syphilis, gonorrhoea , chlamydia, ,HIV,HPV \& herpes simplex carry a potential impact on maternal ,fetal \& neonatal health .During pregnancy there is a change in immunology like decreased cell mediated immunity ,release of Th1 type cytokines \& other pro inflammatory cytokines. Women are more susceptible to infection.

STIs have been associated with spontaneous miscarriage, still birth, prematurity, low birth weight, preterm labor, PROM, post partum endometritis. ${ }^{1}$ So early screening \&treatment of the STI should be done to minimize the Antepartum, Intrapartum, \& Postpartum consequences.

\section{Aim \& Objectives}

To know the pattern of STI by using laboratory tests among pregnant women and to find the socio demographic factors influencing STI.

\section{Materials \& Methods}

A clinical retrospective study was conducted in the pregnant women from January 2013 to June 2015 at tertiary care centre.

Patients were screened according to their age distribution, education, socio economic status, number \& duration of current pregnancy, \& symptoms. This is followed by clinical exam and laboratory investigations like wet mount, $\mathrm{KOH}$ for candida, gram staining, Tzanck smear, culture for gonococci, culture for candida, \& serology .

\section{Results}

Among 11959 female patients, pregnant women were 84(0.7\%).

Majority (83.3\%) were of 25- 35 years age group, followed by $15 \%$ of $<25$ years age. Majority belonged to lower socio economic status ( $86.6 . \%$ )

In our study group most of them were illiterate( $36 \%)$,followed by primary schooling (21\% ) and remaining $15.5 \%, 14.3 \%$, $13.2 \%$ have studied upto High school, Higher secondary, Degree respectively. Among 84 pregnant women, $65.2 \%$ were multigravida and $28.8 \%$ were primigravida.

Most of the study group belonged to second trimester of pregnancy $(67.5 \%)$, followed by $1^{\text {st }}$ trimester $(56.2 \%) \& 3^{\text {rd }}$ trimester (17.8\%) of pregnancy (Fig No. 1) 


\section{International Journal of Science and Research (IJSR) \\ ISSN (Online): 2319-7064}

Index Copernicus Value (2013): 6.14 | Impact Factor (2015): 6.391

\section{DURATION OF PREGNANCY}

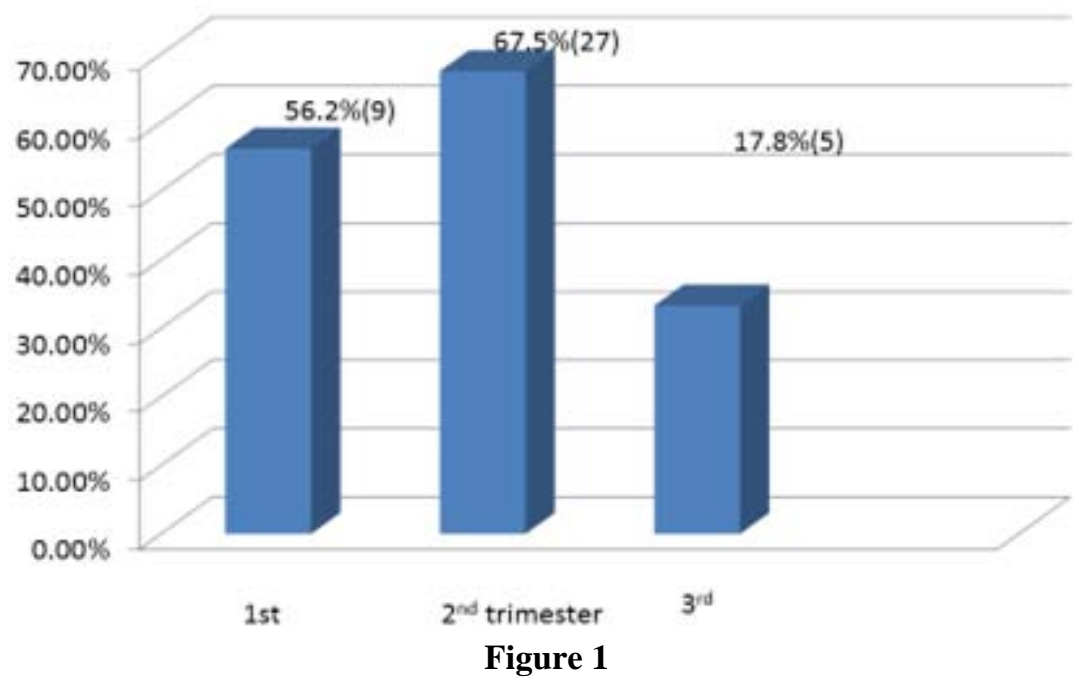

Among 84 pregnant women $85.7 \%$ were aware of STI and HIV and remaining $14.3 \%$ were not aware of STI \& HIV infection.
In the study group only 34 pregnant women had vaginal discharge. Mucoid vaginal discharge was predominant (58.8\%), followed by curdy and frothy discharge each 5.9\% respectively. (Fig No.2)

\section{NATURE OF VAGINAL DISCHARGE $(n=34)$}

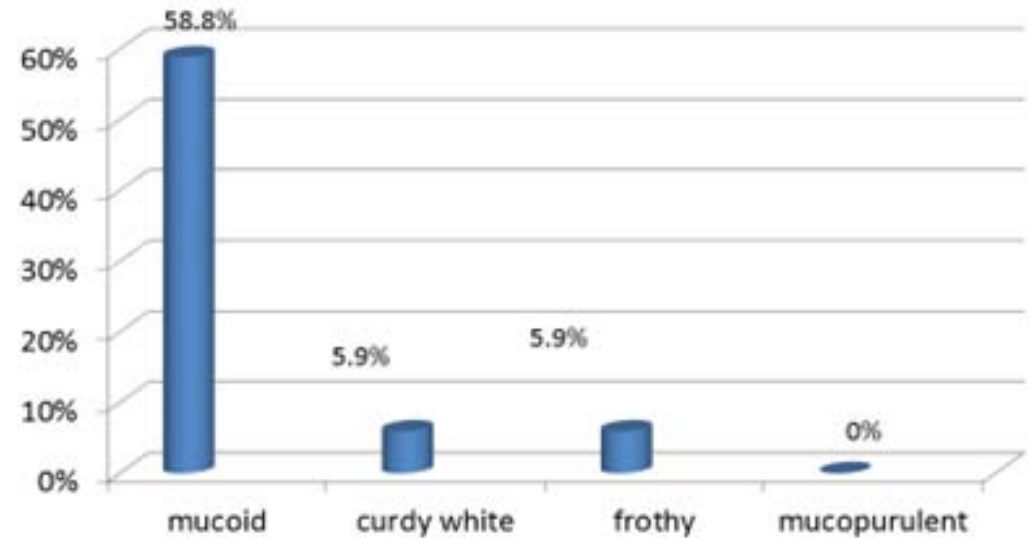

Figure 2

Among the 84 pregnant women $13.09 \%$ were Reactive to Blood VDRL test for Syphilis and 86.91\% were Nonreactive.

Among 84 pregnant women 4 were Reactive for HIV and remaining 80 were Non Reactive for HIV. Individual STI's were diagnosed by clinical and Laboratory examinations and results are tabulated below (Table No.1 )
Table 1: Individual STI diagnosed by clinical exam, laboratory investigations (77.5\%)

\begin{tabular}{|c|c|c|}
\hline & no & $\%$ \\
\hline Genital wart & 10 & 24 \\
\hline syphilis & 9 & 22 \\
\hline candidiasis & 8 & 19 \\
\hline $\begin{array}{l}\text { Molluscum } \\
\text { contagiosum }\end{array}$ & 2 & 5 \\
\hline $\begin{array}{l}\text { Retroviral } \\
\text { disease }\end{array}$ & 1 & 2.5 \\
\hline $\begin{array}{l}\text { Bacterial } \\
\text { vaginosis }\end{array}$ & 1 & 2.5 \\
\hline Trichomoniasis & 1 & 2.5 \\
\hline
\end{tabular}


Pattern of mixed infections (22.5\%) like Early latent syphilis +VVC, VVC+ genital

wart+ genital herpes, HIV+ve + herpes, HIV +ve +genital wart constitute $2.5 \%$ each.

\section{Discussion}

Sexually transmitted infections constitute a major public health problem in developing \& developed countries .Emergence of HIV insist the control of STI in the community. STI including HIV are important in determining the pregnancy outcome in developing countries.Sexually transmitted infections constitute a major public health problem in developing \& developed countries .

From our study, pattern of STI in pregnant women was $48.8 \%$ (41). Our study showed the trend of STI were more in the age group of $25-35$ yrs $(83.3 \%))^{2}$ due to increased sexual activity in this age group. There was increased STI in persons with poor literacy.

Majority of women had STI in $2^{\text {nd }}$ trimester $67.5 \%$ (27) as compared to $1^{\text {st }} \& 3^{\text {rd }}$ trimester. Multigravida had more infections than primigravida citing the association between increased number of parity \& STI. In our study group 75.6\% (31) had symptoms like vaginal discharge , itching , soddening of vulva \& ulcer in the genital area.

Majority of women had genital wart $24 \%(10)^{5,6}$ followed by syphilis $22 \%(9)$ then candidiasis19\%(8). Prevalence of Trichomoniasis was $2.5 \%^{7}$

\section{Conclusion}

This study stresses the importance of Antenatal screening for HIV, Syphilis in $1^{\text {st }} \& 3^{\text {rd }}$ trimester \& partner screening. Safe sex practices including correct, consistent use of condoms should be stressed on Antenatal women and their sexual partner.

\section{References}

[1] Vinod K. Sharma Second Edition SEXUALLY TRANSMITTED DISEASES AND HIV /AIDS pg.no. 4 and 57

[2] Mabey D Sexually transmitted diseases in developing countries Trans R Soc Trop Med Hyg 1996; 90; 97-99

[3] Parmar J, Raval RC, Bilimoria FE. Clinical profile of STD's at Civil Hospital Ahmedabad. Indian J Sex. Trans Dis 2001; 22; 14 -16

[4] Sharma PK. A profile of Sexually Transmitted Diseases at Port Blair. Indian J Sex. Trans Dis 1994 ; 15; 21-22

[5] Fife KH, Rogers RE, Zwickl BW, Symptomatic and asymptomatic cervical infections with human papillomavirus during pregnancy. $\mathrm{J}$ Infect Dis 1987:156:904-11.

[6] Kemp EA, Hakenewerth AM,Laurent SL, et al. Human papillomavirus prevalence in pregnancy . Obstet Gynaecol 1992:79:649-56.)

[7] E. Donbraye, O.O.B. Donbraye Emmanuel- World Applied sciences Journal 2010 11(12); 1512-1517 